\title{
Corylin inhibits LPS-induced inflammatory response and attenuates the activation of NLRP3 inflammasome in microglia
}

\author{
Ming-Yii Huang ${ }^{1,2+}{ }^{+}$Chia-En Tu ${ }^{2 \dagger}$, Shu-Chi Wang ${ }^{3}$, Yung-Li Hung ${ }^{4}$, Chia-Cheng Su ${ }^{2,5,6}$, Shih-Hua Fang ${ }^{7}$,
} Chi-Shuo Chen ${ }^{8}$, Po-Len Liu' ${ }^{9}$, Wei-Chung Cheng ${ }^{10}$, Yu-Wei Huang ${ }^{11}$ and Chia-Yang Li2 ${ }^{2^{*}}$ (I)

\begin{abstract}
Background: Inflammation has been found to be associated with many neurodegenerative diseases, including Parkinson's and dementia. Attenuation of microglia-induced inflammation is a strategy that impedes the progression of neurodegenerative diseases.

Methods: We used lipopolysaccharide (LPS) to simulate murine microglia cells (BV2 cells) as an experimental model to mimic the inflammatory environment in the brain. In addition, we examined the anti-inflammatory ability of corylin, a main compound isolated from Psoralea corylifolia L. that is commonly used in Chinese herbal medicine. The production of nitric oxide (NO) by LPS-activated BV2 cells was measured using Griess reaction. The secretion of proinflammatory cytokines including tumor necrosis factor (TNF-a), interleukin-1 $\beta$ (IL-1 $\beta$ ) and interleukin-6 (IL-6) by LPS-activated BV2 cells was analyzed using enzyme-linked immunosorbent assay (ELISA). The expression of inducible NO synthase (iNOS), cyclooxygenase-2 (COX-2), nucleotide-binding oligomerization domain-like receptor containing pyrin domain 3 (NLRP3), apoptosis-associated speck-like protein containing a caspase-activation and recruitment domain (ASC), caspase-1, IL-1 $\beta$ and mitogen-activated protein kinases (MAPKs) in LPS-activated BV2 cells was examined by Western blot.
\end{abstract}

Results: Our experimental results demonstrated that corylin suppressed the production of $\mathrm{NO}$ and proinflammatory cytokines by LPS-activated BV2 cells. In addition, corylin inhibited the expression of iNOS and COX-2, attenuated the phosphorylation of ERK, JNK and p38, decreased the expression of NLRP3 and ASC, and repressed the activation of caspase-1 and IL-1 $\beta$ by LPS-activated BV2 cells.

Conclusion: Our results indicate the anti-inflammatory effects of corylin acted through attenuating LPS-induced inflammation and inhibiting the activation of NLRP3 inflammasome in LPS-activated BV2 cells. These results suggest that corylin might have potential in treating brain inflammation and attenuating the progression of neurodegeneration diseases.

Keywords: Microglia, Corylin, MAPK signaling pathway, NLRP3 inflammasome, Anti-inflammation

\footnotetext{
* Correspondence: chiayangli@kmu.edu.tw

${ }^{\dagger}$ Ming-Yii Huang and Chia-En Tu contributed equally to this work

${ }^{2}$ Graduate Institute of Medicine, College of Medicine, Kaohsiung Medical

University, Kaohsiung 80708, Taiwan

Full list of author information is available at the end of the article
}

(c) The Author(s). 2018 Open Access This article is distributed under the terms of the Creative Commons Attribution 4.0 International License (http://creativecommons.org/licenses/by/4.0/) which permits unrestricted use, distribution, and reproduction in any medium, provided you give appropriate credit to the original author(s) and the source, provide a link to the Creative Commons license, and indicate if changes were made. The Creative Commons Public Domain Dedication waiver (http://creativecommons.org/publicdomain/zero/1.0/) applies to the data made available in this article, unless otherwise stated. 


\section{Background}

Inflammation has been found to be associated with pathogenesis of various neurodegenerative diseases such as Alzheimer's disease and Parkinson's disease [1]. Microglia, which are the resident macrophages in the central nervous system (CNS), play a critical role in regulating immune response and neuronal homeostasis [2, 3]. Upon the introduction of stimuli such as pathogens, inflammation and brain injury, microglia become rapidly activated and initiate an inflammatory cascade in response to exogenous or endogenous stimuli such as pathogens, inflammation and brain injury [4]. The activated microglia secrete several inflammatory cytokines and neurotoxic mediators such as tumor necrosis factor- $\alpha$ (TNF- $\alpha$ ), interleukin-1 $\beta$ (IL-1 $\beta$ ), IL-6 and nitric oxide (NO), while augmenting neurodegeneration and neuronal death [5-7]. The germline-encoded pattern recognition receptors and Toll-like receptor 4 (TLR4) are not only a major receptor in detection of bacterial component lipopolysaccharides (LPS), but also recognize heat-shock proteins and other danger-associated molecular patterns from damaged cells. TLR4 mediates several inflammatory signaling pathways and produces pro-inflammatory cytokines and mediators in response to infection, injury and toxin. Especially, TLR4 recognizes extracellular deposits of insoluble amyloid- $\beta$, which is a pivotal contributor to Alzheimer's disease, and activates microglia [8]. Therefore, TLR4 activation critically contributes to neurodegeneration and neuronal death $[9,10]$, and is involved in development of neurodegenerative diseases $[11,12]$.

In TLR4-mediated inflammatory signaling pathways, mitogen-activated protein kinases (MAPKs) crucially regulate the production of pro-inflammatory cytokines and mediators [13]. The activated MAPKs trigger downstream transcription factors such as activator protein 1 and nuclear factor- $\mathrm{kB}(\mathrm{NF}-\mathrm{\kappa B})$, and produce pro-inflammatory cytokines and mediators [14]. Additionally, inducible NO synthase (iNOS) and cyclooxygenase-2 (COX-2) are produced and synthesize neurotoxic mediators $\mathrm{NO}$ and prostaglandin $\mathrm{E}_{2}\left(\mathrm{PGE}_{2}\right)$ by TLR4-mediated inflammatory signaling respectively [15]. Therefore, targeting the TLR4 signaling pathway is considered a method of improving neuroinflammation-related diseases [16].

On the other hand, the nucleotide-binding oligomerization domain-like receptor containing pyrin domain 3 (NLRP3) inflammasome is an essential regulator to produce IL-1 $\beta$ and is considered to regulate the progression of several neurodegenerative diseases [17]. The bacterial LPS or amyloid- $\beta$ induce TLR4 signaling transduction pathway, mediate NF- $\mathrm{KB}$ activity, and produce NLRP3 and IL-1 $\beta$ precursors. NLRP3, an apoptosis-associated speck-like protein containing a caspase-activation and recruitment domain (ASC), and pro-caspase-1 combine to form an NLRP3 inflammasome complex [18]. Additionally, necrotic cells release ATP and trigger P2X7 receptor signaling, and then pro-caspase- 1 is converted into activated caspase- 1 . The activated caspase-1 cleaves IL-1 $\beta$ precursors and converts these into mature IL-1 $\beta$ [19]. The secretion of IL- $1 \beta$ augments inflammation and neurotoxicity, while leading to neurodegeneration and neuronal death. Thus, the inhibition of NLRP3 inflammasome is considered a therapeutic target of neurodegenerative diseases $[17,19,20]$.

Nonsteroidal anti-inflammatory drugs (NSAIDs) have been demonstrated to exhibit neuroprotective effects, but long-term NSAID treatment might induce side effects [4]. Flavonoids are abundantly present in plant, fruits and vegetables, and have been indicated to exert several types of anti-inflammatory effects $[21,22]$. Psoralea corylifolia L. has been widely used as a kidney tonifying herbal medicine for treating many diseases such as osteoporosis [23], leucoderma and inflammatory diseases of the skin in Asian countries [24]. Corylin is a main flavonoid that is isolated from Psoralea corylifolia L. Previous studies indicated that corylin has various pharmaceutical effects, including anti-cancer $[25,26]$ and anti-inflammatory properties [27, 28]. However, the anti-inflammatory effects of corylin on microglia remain unclear.

In this study, we investigated the effects of corylin on LPS-induced inflammation by murine brain microglia, BV2 cells. Firstly, we evaluated the effects of corylin on the production of pro-inflammatory cytokines (TNF- $\alpha$, IL-6 and IL-1 $\beta$ ) and a neurotoxic mediator (NO) by LPS-activated BV2 cells. Secondly, we examined the effects of corylin on the expression of iNOS, COX-2 and MAPKs by LPS-activated BV2 cells. Finally, we tested the effect of corylin on the activation of NLRP3 inflammasome by LPS-activated BV2 cells.

\section{Methods \\ Reagents}

DMEM, penicillin, and streptomycin purchased from Gibco-BRL (Life Technologies, Grand Island, NY, USA). Fetal bovine serum (FBS) was purchased from Hyclone Laboratories (Logan, UT, USA). LPS (from E. coli 0111:B4), Griess reagent, 3-(4, 5-dimethylthiazol-2-yl)-2, 5-diphenyl tetrazolium bromide (MTT), RIPA buffer, protease inhibitors, and phosphatase inhibitors were purchased from Sigma Aldrich (St. Louis, MO, USA). TNF- $\alpha$, IL- 6 and IL-1 $\beta$ ELISA kits were purchased from eBioscience (San Diego, CA, USA). BCA protein assay kit, ECL chemiluminescence substrate, and Hoechst 33,342 were obtained from Thermo Scientific (Waltham, MA, USA). Rabbit antibodies against mouse iNOS, COX-2, ASC, IL-1 $\beta, \beta$-actin and secondary antibodies were obtained from Santa Cruz Biotechnology (Santa Cruz, CA, USA). Rabbit antibodies against mouse phospho-JNK, JNK, phospho-p38 MAPK, p38 MAPK, phospho-ERK, ERK, NLRP3 and caspase-1 (p20) were purchased from Cell Signaling (Farmingdale, 
NY, USA). Corylin (purity >98\%) was obtained from ChemFaces (Wuhan, Hubei, China) and analyzed by the Limulus amebocyte lysate assay (Associates of Cape Cod, Falmouth, MA, USA) to avoid the possibility of endotoxin contamination. Results indicated that corylin had undetectable level of endotoxin $(<0.03 \mathrm{EU} / \mathrm{mL}$, data not shown). For the treatment of corylin, corylin was dissolved in DMSO at a stock concentration of $50 \mathrm{mM}$, then further diluted in the culture medium at a final DMSO concentration of $\leq 0.02 \%$.

\section{Cell culture}

Murine BV2 microglial cells were purchased from the Food Industry Research and Development Institute (Hsinchu, Taiwan) and cultured in DMEM supplemented with $10 \%$ FBS and antibiotics $(100 \mathrm{U} / \mathrm{mL}$ penicillin and $100 \mathrm{U} / \mathrm{mL}$ streptomycin) in a humidified atmosphere of $5 \% \mathrm{CO}_{2}$ at $37{ }^{\circ} \mathrm{C}$ and passaged every $2-3$ days to maintain growth.

\section{NO assay}

The Griess assay measures the level of accumulated nitrite $\left(\mathrm{NO}_{2}^{-}\right)$, a metabolite of $\mathrm{NO}$, in culture supernatant by the Griess reagent. BV2 cells were seeded in a 96-well plate at a density of $1 \times 10^{5}$ cells per well and incubated overnight. Cells were pre-treated with various concentrations of corylin $(0$ to $10 \mu \mathrm{M})$ for $1 \mathrm{~h}$, and then were treated with LPS $(1 \mu \mathrm{g} / \mathrm{mL})$ for $24 \mathrm{~h}$. The supernatant of cell culture was collected and the concentration of $\mathrm{NO}$ was measured by the Griess reagent.

\section{MTT assay}

BV2 cells were seeded in a 96-well plate at a density of $1 \times 10^{5}$ cells per well and incubated overnight. Cells were pre-treated with various concentrations of the corylin $(0$ to $10 \mu \mathrm{M}$ ) for $1 \mathrm{~h}$, and then treated with LPS $1 \mu \mathrm{g} / \mathrm{mL}$ for $24 \mathrm{~h}$. Cell viability was assayed by MTT assay following the manufacturer's instructions (Sigma, St. Louis, MO, USA). Cell viability was calculated using the equation: (mean OD of treated cells/mean OD of control cells) $\times 100$.

\section{Enzyme-linked Immunosorbent assay (ELISA)}

BV2 cells were seeded in 96-well plate at a density of $1 \times 10^{5}$ cells per well and incubated overnight. Cells were pre-treated with different concentrations (0 to $10 \mu \mathrm{M}$ ) of corylin for $1 \mathrm{~h}$, and then treated with LPS $1 \mu \mathrm{g} / \mathrm{mL}$ for $24 \mathrm{~h}$. The supernatant of cell culture was collected and analyzed by ELISA according to the manufacturer's protocol (eBioscience, San Diego, CA, USA).

\section{Western blotting}

Cells were lysed by RIPA buffer with protease inhibitors and phosphatase inhibitors and the concentration of protein was evaluated using the BCA protein assay reagent following the manufacturer's instructions (Thermo Scientific, Waltham, MA, USA). Aliquots of equal amounts of proteins from the cells were subjected to SDS-PAGE. Thereafter, proteins were electrophoretically transferred to PVDF membranes. The membranes were incubated with $5 \%$ skim milk to block nonspecific protein binding and incubated with primary antibodies at $4{ }^{\circ} \mathrm{C}$ overnight. After washing 3 times with Tris-buffered saline/Tween 20 (TBST), the blots were hybridized with horseradish peroxidase-conjugated secondary antibodies for $1 \mathrm{~h}$ at room temperature. Then, the blots were washed three times with TBST, and the specific immunoreactive protein bands were detected by ECL chemiluminescence substrate. The signals were captured and the band intensities were quantified using Bio-Rad ChemiDoc $\mathrm{XRS}^{+}$system (Bio-Rad Laboratories, Inc., Hercules, CA, USA).

\section{Immunofluorescence staining}

The formation of inflammasome was imaged by ASC/ caspase-1 immunofluorescence staining. BV2 cells were seeded on 12-mm glass coverslips in 24 well-plates overnight. Cells were incubated with $10 \mu \mathrm{M}$ corylin prior to LPS treatment $(1 \mu \mathrm{g} / \mathrm{mL})$ for $24 \mathrm{~h}$. Then, cells were fixed with $4 \%$ paraformaldehyde and permeabilized using $0.2 \%$ Triton X-100 in PBS, and cells were incubated with anti-ASC and anti-caspase-1 primary antibodies overnight. Then, cells were washed with PBS to remove the excessive primary antibodies, and incubated with fluorescent secondary antibodies. The cell nucleus was labeled with Hoechst 33,342. High magnification fluorescent images were taken using an inverted epi-fluorescent microscope (Nikon-Ti, Nikon, Japan) with $60 \times$ oil immersion objectives. The localization and expression of ASC and caspase-1 were processed using NIS-Elements software (Nikon, Japan) and ImageJ software (National Institutes of Health, Bethesda, MD, USA).

\section{Statistical analysis}

All experiments were performed at least in triplicate, with data presented as mean \pm standard deviation (SD) of independent experiments and analyzed using IBM SPSS Statistics v.19 (IBM Corp., Armonk, NY, USA). Comparisons between control and treatment groups were made using Student's $t$-test. The significant difference was set at ${ }^{*}: p<0.05 ;{ }^{* * *}: p<0.01 ;{ }^{* * *}: p<0.001$.

\section{Results}

Corylin inhibits the production of $\mathrm{NO}$ and the expression of iNOS and COX-2 in LPS-activated murine microglial cells

To avoid the toxic effects of corylin, we performed MTT assay to examine the cell survival after corylin and LPS 
treatments. BV2 cells were pre-treated with corylin at different doses $(0$ to $10 \mu \mathrm{M})$ for $1 \mathrm{~h}$, and then treated with LPS $1 \mu \mathrm{g} / \mathrm{mL}$ for $24 \mathrm{~h}$. As shown in Fig. 1a, there was no toxic effect of corylin when BV2 cells were treated with corylin 0 to $10 \mu \mathrm{M}$. In addition, corylin protected BV2 cells against LPS-induced cell death (Fig. 1a). Both iNOS and COX-2 are critical inflammation-related enzymes involved in producing nitric oxide and prostaglandins respectively [15]. To examine the effect of corylin on LPS-induced NO production, BV2 cells were pre-treated with various doses of corylin $(0$ to $10 \mu \mathrm{M})$ for $1 \mathrm{~h}$, and then stimulated with LPS $(1 \mu \mathrm{g} / \mathrm{mL})$ for $24 \mathrm{~h}$. The production of $\mathrm{NO}$ was analyzed by Griess reagent assay. Our experimental results showed that corylin significantly suppressed the production of NO by LPS-stimulated BV2 cells in a dose-dependent manner (Fig. 1b). We further examined the effect of corylin on the expression of iNOS and COX-2 using Western blot. Our results indicated that corylin suppressed the expression of iNOS and COX-2 by LPS-stimulated BV2 cells, as compared with LPS alone (Fig. 1c, d and e).

\section{Corylin represses LPS-induced production of pro-inflammatory cytokines in murine microglial cells}

Since TNF- $\alpha$ and IL- 6 are critical pro-inflammatory cytokines in response to LPS, we further tested whether corylin affected the production of pro-inflammatory cytokines induced by LPS in murine microglial cells. BV2 cells were pre-treated with various concentrations of corylin for $1 \mathrm{~h}$, and then treated with LPS $(1 \mu \mathrm{g} / \mathrm{mL})$ for $24 \mathrm{~h}$. The production of TNF- $\alpha$ and IL- 6 was determined by ELISA. As shown in Fig. 2, corylin inhibited both TNF- $\alpha$ and
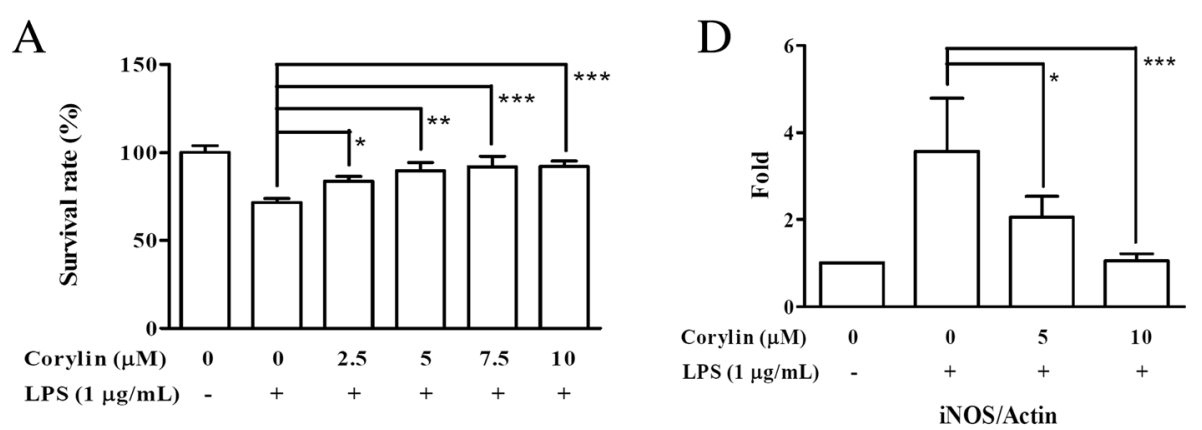

B
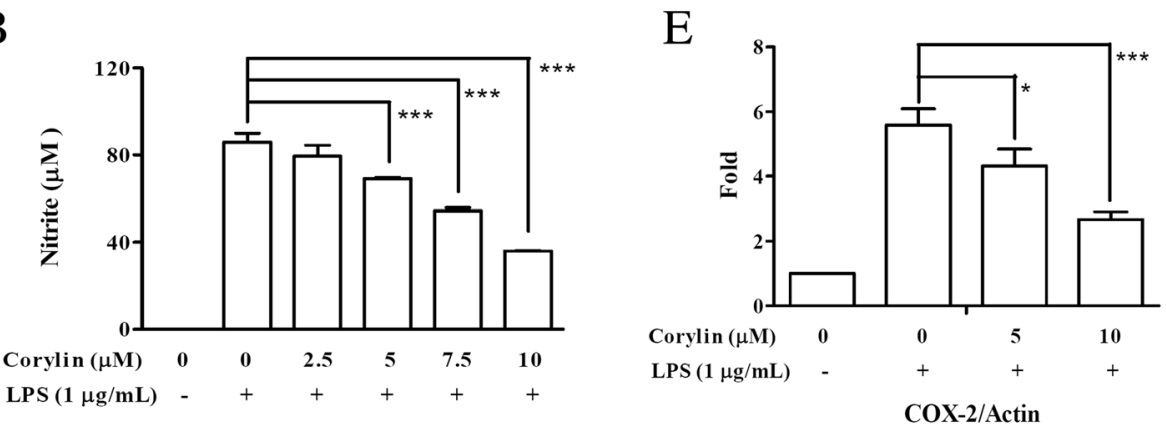

C

\begin{tabular}{llllll} 
Corylin $(\mu \mathrm{M})$ & 0 & 0 & 5 & 10 \\
$\operatorname{LPS}(1 \mu \mathrm{g} / \mathrm{mL})$ & - & + & + & + \\
\hline iNOS & + \\
Actin & - & - \\
\hline COX -2 & \\
Actin & - \\
\hline
\end{tabular}

Fig. 1 Effects of corylin on the cell viability and the production of NO by LPS-activated BV2 cells. BV2 cells were pre-treated with various doses of corylin for $1 \mathrm{~h}$, and then treated with LPS $(1 \mu \mathrm{g} / \mathrm{mL})$ for $24 \mathrm{~h}$. a The survival rate of BV2 cells was measured by MTT assay. $\mathbf{b}$ The production of NO in the cell culture supernatant was detected by Griess reaction. c The expression of COX-2 and iNOS was examined by Western blot. Blots are representative blots. The relative ratio of $(\mathbf{d})$ iNOS $/ \beta$-actin and (e) COX-2/ $\beta$-actin are shown. Data represent mean \pm SD of three independent experiments (*: $p<0.05 ;{ }^{* *}: p<0.01 ;{ }^{* * *}: p<0.001$ vs. LPS alone) 

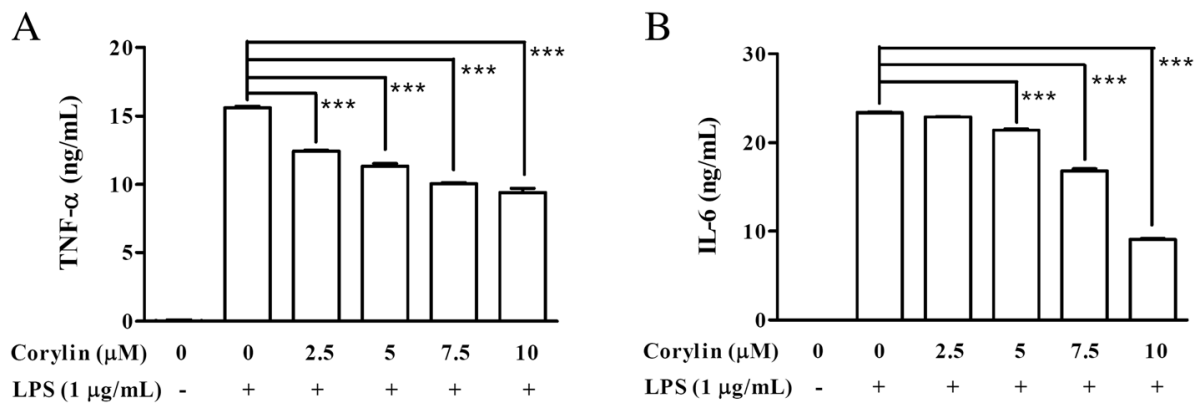

Fig. 2 Effects of corylin on the production of proinflammatory cytokines by LPS-activated BV2 cells. BV2 cells were pre-treated with various doses of corylin for $1 \mathrm{~h}$, and then treated with LPS $(1 \mu \mathrm{g} / \mathrm{mL})$ for $24 \mathrm{~h}$. The expressions of $\mathbf{a}$ TNF-a and $\mathbf{b} \mathrm{IL}-6$ in the cell culture supernatant were analyzed using ELISA. Data represent mean \pm SD of three independent experiments $\left({ }^{*}: p<0.05 ;{ }^{* *}: p<0.01 ;{ }^{* *}: p<0.001\right.$ vs. LPS alone)

IL-6 production by LPS-activated BV2 cells in a concentration-dependent manner.

\section{Corylin suppresses the phosphorylation of MAPKs by LPS-activated murine microglial cells}

MAPKs (JNK, p38 MAPK and ERK) phosphorylate a wide range of substrate proteins including transcription factors, which play an important role in regulating inflammatory responses and modulating the production of pro-inflammatory mediators and cytokines [29]. To investigate the effect of corylin on the activation of MAPKs, BV2 cells were incubated with various doses of corylin for $1 \mathrm{~h}$, and then treated with LPS $(1 \mu \mathrm{g} / \mathrm{mL})$ for $24 \mathrm{~h}$. The expression levels of phospho-JNK, JNK, phospho-p38 MAPK, p38 MAPK, phospho-ERK and ERK were examined by Western blot. As shown in Fig. 3, the phosphorylation of JNK, p38 MAPK and ERK was markedly elevated after LPS stimulation. Treatment with corylin $(5$ and $10 \mu \mathrm{M})$ significantly decreased LPS-induced phosphorylation of JNK, p38 MAPK and ERK in BV2 cells (Fig. 3).
A

\begin{tabular}{|c|c|c|c|c|}
\hline Corylin $(\mu \mathrm{M})$ & 0 & 0 & 5 & 10 \\
\hline $\operatorname{LPS}(1 \mu \mathrm{g} / \mathrm{mL})$ & - & + & + & + \\
\hline phospho-ERK & & - & $=$ & $\underline{E}$ \\
\hline ERK & 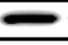 & - & $=$ & 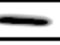 \\
\hline phospho-JNK & 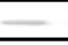 & $=$ & $=$ & $\bar{E}$ \\
\hline JNK & $\overline{=}$ & $\bar{E}$ & $\overline{\bar{E}}$ & $\overline{\bar{E}}$ \\
\hline phospho-p38 & & $=$ & 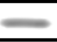 & \\
\hline p38 & - & 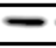 & & \\
\hline
\end{tabular}

B

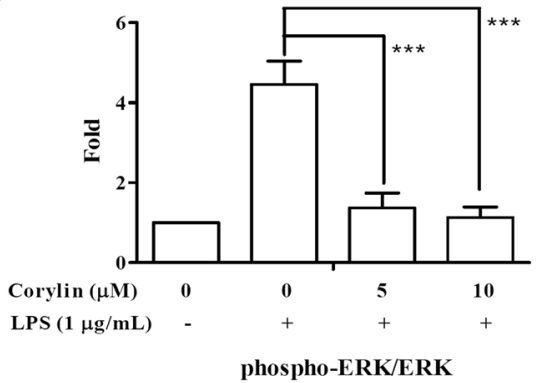

C

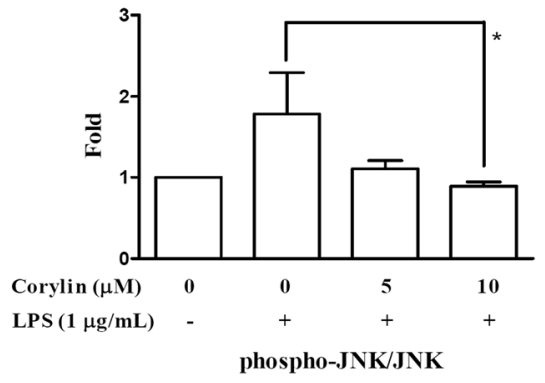

$\mathrm{D}$

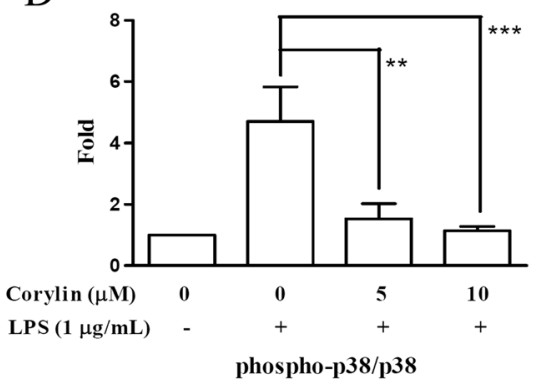

Fig. 3 Effects of corylin on MAPK signaling pathway by LPS-activated BV2 cells. Cells were incubated with various doses of corylin for $1 \mathrm{~h}$, and then treated with LPS $(1 \mathrm{\mu g} / \mathrm{mL})$ for $24 \mathrm{~h}$. a Western blot analysis of phospho-JNK, JNK, phospho-p38 MAPK, p38 MAPK, phospho-ERK and ERK. Blots are representative blots. $\mathbf{b}, \mathbf{c}, \mathbf{d}$ Quantitation was performed on three independent experiments and presented as the means \pm SD. The relative fold was phosphorylation to dephosphorylation ratio and compared to untreated samples $\left(*: p<0.05 ;{ }^{* *}: p<0.01 ;{ }^{* * *}: p<0.001\right.$ vs. LPS alone) 


\section{Corylin suppresses the production of IL-1 $\beta$ through attenuating the activation of NLRP3 inflammasome in murine microglial cells}

IL-1 $\beta$ is a critical proinflammatory cytokine, which subsequently enhances the production of both TNF- $\alpha$ and IL-6 [30] and promotes the generation of reactive oxygen species by microglia causing severe tissue and organ damage [20]. To investigate whether corylin affects the production of IL-1 $\beta$ by LPS-activated murine microglial cells, BV2 cells were pre-treated with various concentrations of corylin for $1 \mathrm{~h}$, and then treated with LPS $(1 \mu \mathrm{g} / \mathrm{mL})$ for $48 \mathrm{~h}$. The production of IL- $1 \beta$ was analyzed by ELISA. As shown in Fig. 4a, corylin suppressed the production of IL- $1 \beta$ by LPS-activated BV2 cells. The activation of NLRP3 inflammasome is an important innate immune pathway, which is critical for the production of active IL- $1 \beta$, and is considered as a key contributor to the development of neuroinflammation [31]. We further examined whether corylin affects the activation of NLRP3 inflammasome in LPS-activated BV2 cells. Our results indicated that corylin reduced the expression of NLRP3 and ASC by
LPS-activated BV2 cells (Fig. 4b, c and d). In addition, we also found that corylin decreased the expression of mature caspase- 1 and mature IL- $1 \beta$ by LPS-activated BV2 cells (Fig. 4e, $\mathrm{f}$ and g). Moreover, we also confirmed that corylin inhibited the expression of NLRP3 using immunofluorescent staining (Fig. 5a) and demonstrated corylin inhibited the formation of inflammasome complex in LPS-activated BV2 cells (Fig. 5b).

\section{Discussion}

Corylin, a main flavonoid isolated from Psoralea corylifolia L., has been demonstrated to exhibit various biological properties such as anti-tumor $[25,26]$ and anti-inflammatory effects [27, 28]; however, the effect of corylin on LPS-activated microglia has not been examined. To our knowledge, this is the first report indicating that corylin inhibits LPS-induced inflammatory response and attenuates the activation of NLRP3 inflammasome in murine brain microglia.

Activated microglia cause neuronal cell degeneration by secreting various pro-inflammatory cytokines and neurotoxic mediators [32]. In the present study, our
A

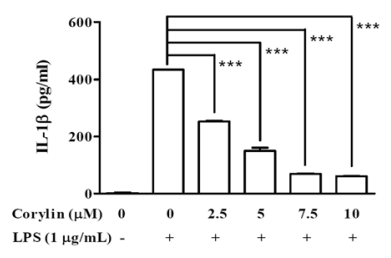

B

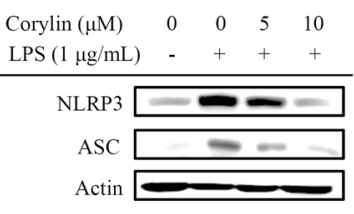

$\mathrm{C}$

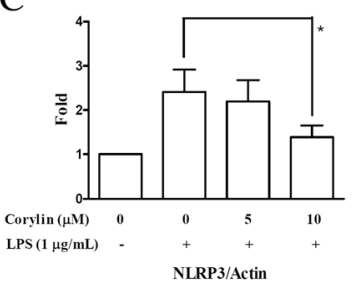

D

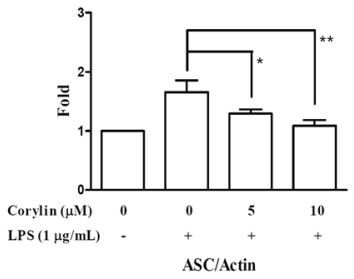

$\mathrm{E}$

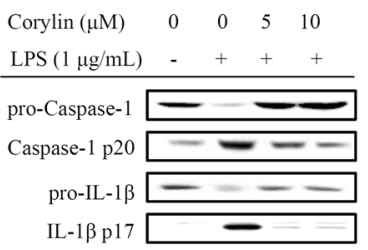

F

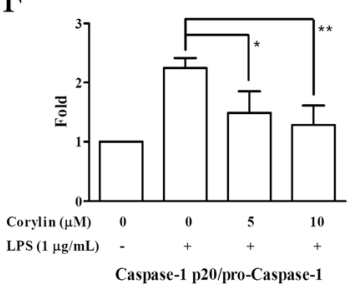

G

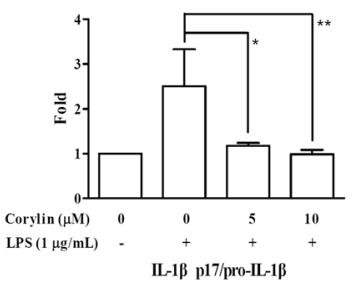

IL-1 1 p17/pro-IL-1 $\beta$

Fig. 4 Effects of corylin on the activation of NLRP3 inflammasome by LPS-activated BV2 cells. BV2 cells were incubated with various doses of corylin for $1 \mathrm{~h}$, and then treated with LPS $(1 \mu \mathrm{g} / \mathrm{mL})$ for $24 \mathrm{~h}$ or $48 \mathrm{~h}$. a The level of IL-1 $\beta$ in the cell culture supernatant was examined by ELISA (***: $p<0.001$ vs. LPS alone). b The expression levels of NLRP3 and ASC were examined by Western blot. Blots are representative blots. $\mathbf{c}$, $\mathbf{d}$ Quantitation was performed on three independent experiments and presented as the means \pm SD. The expression of $\beta$-actin was used as an internal control. The relative ratios of NLRP3/ $\beta$-actin and ASC/ $\beta$-actin are shown (*: $p<0.05 ;{ }^{* *}: p<0.01$ vs. LPS alone). e The expression levels of pro-caspase-1, mature caspase-1 (p20), pro-IL-1 $\beta$, and mature IL-1 $\beta$ (p17) were examined by Western blot. Blots are representative blots. Quantitation was performed on three independent experiments and presented as the means \pm SD. The relative ratio of $\mathbf{f}$ mature caspase- 1 (p20)/immature caspase-1 and $\mathbf{g}$ mature IL-1 $\beta$ (p17)/immature IL-1 $\beta$ are shown (*: $p<0.05 ;{ }^{* *}: p<0.01$ vs. LPS alone) 


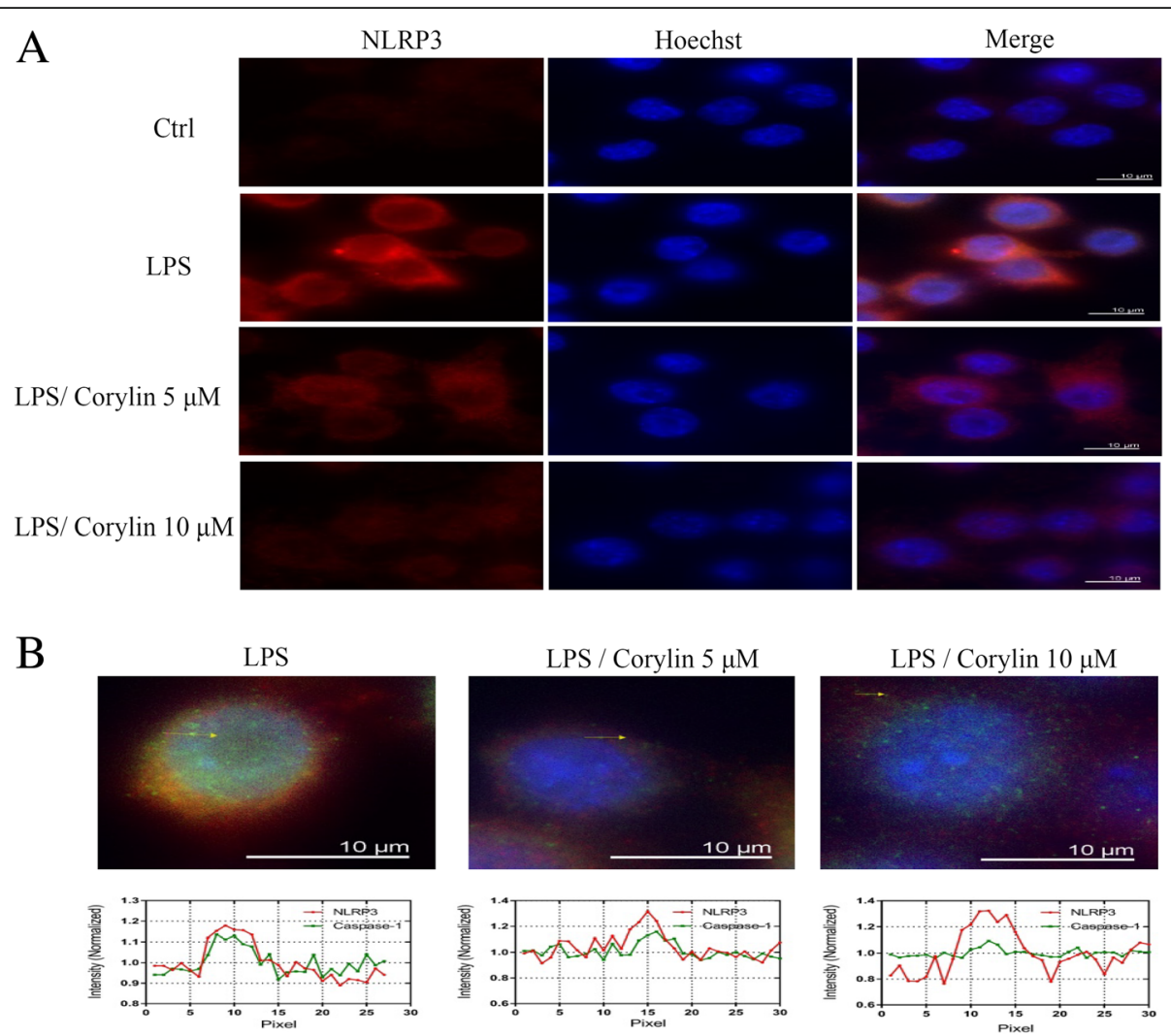

Fig. 5 Effects of corylin on the expression of NLRP3 and colocalization of NLRP3 with caspase-1 (green) in LPS-activated BV2 cells. Cells were incubated with various doses of corylin for $1 \mathrm{~h}$, and then treated with LPS $(1 \mu \mathrm{g} / \mathrm{mL})$ for $24 \mathrm{~h}$. a Representative fluorescent microscopy images showing the expression of NLRP3 (red) in LPS-activated BV2 cells. The nuclei were stained with Hoechst 33,342 (blue). b Representative fluorescent microscopy images showing the colocalization of NLRP3 (red) with caspase-1 (green) in LPS-activated BV2 cells. The nuclei were stained with Hoechst 33,342 (blue). Scale bars, $10 \mu \mathrm{m}$

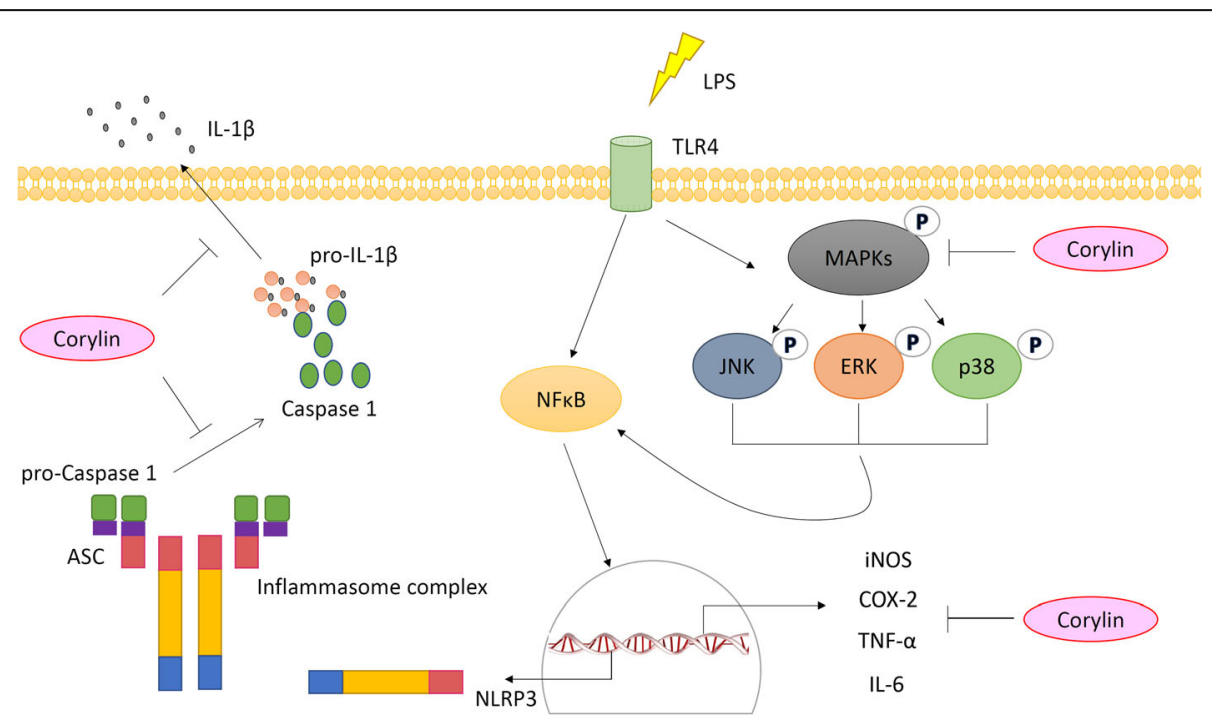

Fig. 6 The potential mechanisms of corylin in suppression of LPS-induced inflammation and NLRP3 activation in microglia 
results demonstrated that corylin inhibited the production of NO and suppressed the expression of iNOS and COX-2, meanwhile decreasing the secretion of TNF- $\alpha$ and IL-6 in LPS-activated murine microglial cells. As similar to our previous study, we found that corylin inhibits the expression of iNOS and COX-2 and decreases the production of $\mathrm{NO}$ and $\mathrm{PGE}_{2}$, and suppresses the secretion of TNF- $\alpha$ and IL- 6 by LPS-activated macrophages [28]. Various research evidence indicates that higher concentrations of $\mathrm{NO}$ and COX-2 have neurotoxic effects and are associated with several neurodegeneration diseases [33-35]. In addition, a local release of proinflammatory cytokines (TNF $\alpha$ and IL6) causes the recruitment of leukocytes across the blood-brain barrier and amplifies the inflammatory reaction, consequently leading to neuro-inflammatory processes consequently [36]. Taken together, these results suggest that corylin could suppress the production of neurotoxic mediators (NO and COX-2) and pro-inflammatory cytokines (TNF- $\alpha$ and IL-6) during inflammation and might have benefits in attenuating neurotoxic effects.

MAPK cascade and its linked downstream transcription factor, NF- $\kappa B$, play an important role in regulating the expression and production of several pro-inflammatory cytokines and mediators $[14,29]$. In the present study, our results indicated that corylin significantly decreased LPS-induced phosphorylation of JNK, p38 MAPK and ERK by microglia. In addition, our previous study also demonstrated that corylin attenuates the phosphorylation of MAPKs by LPS-activated macrophages [28]. Moreover, corylin also suppresses the activation of NF-kB by LPS-activated macrophages [28]. Collectively, these results highlight that corylin inhibits LPS-induced pro-inflammatory cytokines and mediators through inhibition of MAPKs and NF- $\mathrm{B}$ signaling pathways in both macrophages and microglia.

NLRP3 inflammasome is the main regulator to produce IL- $1 \beta$ and is considered to regulate the progression of several neurodegenerative diseases [17, 37]. Our results demonstrated that corylin inhibits the production of IL- $1 \beta$ by LPS-activated microglia. In addition, we also found that corylin suppresses the expression of NLRP3, ASC, mature caspase- 1 and mature IL- $1 \beta$ by LPS-activated microglia. These results demonstrate that corylin inhibits the production of IL- $1 \beta$ through attenuating the activation of the NLRP3 inflammasome.

\section{Conclusion}

The results of the present study showed that corylin inhibits LPS-induced inflammatory responses including decreasing the production of inflammatory mediators (NO), suppressing the expression of iNOS and COX-2, and inhibiting the secretion of proinflammatory cytokines (TNF- $\alpha$, IL-6, and IL-1 $\beta$ ) in murine microglial cells. In addition, corylin attenuated the activation of both MAPKs and NLRP3 inflammasome pathways in LPS-activated murine microglial cells (Fig. 6). Collectively, these results suggest that corylin has potential to inhibit neuroinflammation and might have significant benefits in treating neurodegeneration diseases.

\section{Abbreviations \\ ASC: Apoptosis-associated speck-like protein containing a caspase-activation and recruitment domain; COX-2: Cyclooxygenase-2; ELISA: Enzyme-linked immunosorbent assay; FBS: Fetal bovine serum; IL-1 $\beta$ : Interleukin-1 1 ; IL- 6: Interleukin-6; iNOS: Inducible NO synthase; LPS: Lipopolysaccharide; MAPKs: Mitogen-activated protein kinases; MTT: 3-(4, 5-dimethylthiazol- 2-yl)- 2, 5-diphenyl tetrazolium bromide; NF-kB: Nuclear factor-KB; \\ NLRP3: Nucleotide-binding oligomerization domain-like receptor containing pyrin domain 3; NO: Nitric oxide; NSAIDs: Nonsteroidal anti-inflammatory drugs; PGE2: Prostaglandin E2; SD: Standard deviation; TBST: Tris-buffered saline/Tween 20; TLR4: Toll-like receptor 4; TNF-a: Tumor necrosis factor}

\section{Acknowledgements}

Not applicable.

\section{Funding}

This study was supported by Kaohsiung Medical University (Grant No. KMU-M106023), Kaohsiung Medical University Hospital (Grant No. KMUH106-6R72), China Medical University (Grant No. CMU106-N-05), and Ministry of Science and Technology, Taiwan, R.O.C. (Grant No. MOST 106-2320-B-037-020, 106-2221-E-039-011-MY3 and MOST 106-2314-B-037-019).

\section{Availability of data and materials}

The datasets used and/or analysed during the current study available from the corresponding author on reasonable request.

\section{Authors' contributions}

MYH, CCS, SHF and CYL designed the study; CET, CSC, PLL, WCC and YWH performed the experiments; MYH, CET, SCW, YLH and CYL contributed to manuscript preparation. All authors have read and approved the final manuscript.

Ethics approval and consent to participate

Not applicable.

Consent for publication

Not applicable.

Competing interests

The authors declare that they have no competing interests.

\section{Publisher's Note}

Springer Nature remains neutral with regard to jurisdictional claims in published maps and institutional affiliations.

\section{Author details}

${ }^{1}$ Department of Radiation Oncology, Cancer Center, Kaohsiung Medical University Hospital, Kaohsiung Medical University, Kaohsiung 80708, Taiwan. ${ }^{2}$ Graduate Institute of Medicine, College of Medicine, Kaohsiung Medical University, Kaohsiung 80708, Taiwan. ${ }^{3}$ Department of Medical Laboratory Science and Biotechnology, Kaohsiung Medical University, Kaohsiung 80708, Taiwan. ${ }^{4}$ Institute of Health and Sports Science \& Medicine, Juntendo University, Chiba 270-1695, Japan. ${ }^{5}$ Division of Urology, Department of Surgery, Chi-Mei Medical Center, Tainan 71004, Taiwan. ${ }^{6}$ Department of Senior Citizen Service Management, Chia Nan University of Pharmacy and Science, Tainan 71710, Taiwan. ${ }^{7}$ Institute of Athletics, National Taiwan University of Sport, Taichung 40404, Taiwan. ${ }^{8}$ Department of Biomedical Engineering and Environmental Sciences, National Tsing Hua University, Hsinchu 30013, Taiwan. ${ }^{9}$ Department of Respiratory Therapy, College of Medicine, Kaohsiung Medical University, Kaohsiung 80708, Taiwan.

${ }^{10}$ Graduate Institute of Biomedical Sciences, Research Center for Tumor Medical Science, and Drug Development Center, China Medical University, 
Taichung 40402, Taiwan. ${ }^{11}$ Department of Radiation Oncology, Kaohsiung Chang Gung Memorial Hospital, Kaohsiung 83301, Taiwan.

Received: 31 May 2018 Accepted: 12 July 2018

Published online: 15 August 2018

\section{References}

1. Chen WW, Zhang $X$, Huang WJ. Role of neuroinflammation in neurodegenerative diseases (review). Mol Med Rep. 2016;13(4):3391-6.

2. Chen Z, Trapp BD. Microglia and neuroprotection. J Neurochem. 2016; 136(Suppl 1):10-7.

3. Lee KW, Jung SY, Choi SM, Yang EJ. Effects of ginsenoside re on LPSinduced inflammatory mediators in BV2 microglial cells. BMC Complement Altern Med. 2012;12:196.

4. Kempuraj D, Thangavel R, Natteru PA, Selvakumar GP, Saeed D, Zahoor H, Zaheer S, Iyer SS, Zaheer A. Neuroinflammation Induces Neurodegeneration. J Neurol Neurosurg Spine. 2016;1(1):1003.

5. Kumagai N, Chiba Y, Hosono M, Fujii M, Kawamura N, Keino H, Yoshikawa K, Ishii S, Saitoh Y, Satoh M, et al. Involvement of pro-inflammatory cytokines and microglia in an age-associated neurodegeneration model, the SAMP10 mouse. Brain Res. 2007;1185:75-85.

6. Liberatore GT, Jackson-Lewis V, Vukosavic S, Mandir AS, Vila M, McAuliffe WG, Dawson VL, Dawson TM, Przedborski S. Inducible nitric oxide synthase stimulates dopaminergic neurodegeneration in the MPTP model of Parkinson disease. Nat Med. 1999;5(12):1403-9.

7. Bruccoleri A, Harry GJ. Chemical-induced hippocampal neurodegeneration and elevations in TNFalpha, TNFbeta, IL-1alpha, IP-10, and MCP-1 mRNA in osteopetrotic (op/op) mice. J Neurosci Res. 2000;62(1):146-55.

8. Reed-Geaghan EG, Savage JC, Hise AG, Landreth GE. CD14 and toll-like receptors 2 and 4 are required for fibrillar A\{beta\}-stimulated microglial activation. J Neurosci. 2009;29(38):1 1982-92.

9. Lehnardt S, Massillon L, Follett P, Jensen FE, Ratan R, Rosenberg PA, Volpe $\mathrm{JJ}$, Vartanian T. Activation of innate immunity in the CNS triggers neurodegeneration through a toll-like receptor 4-dependent pathway. Proc Natl Acad Sci U S A. 2003;100(14):8514-9.

10. Lehnardt S, Schott E, Trimbuch T, Laubisch D, Krueger C, Wulczyn G, Nitsch $R$, Weber JR. A vicious cycle involving release of heat shock protein 60 from injured cells and activation of toll-like receptor 4 mediates neurodegeneration in the CNS. J Neurosci. 2008;28(10):2320-31.

11. Huang NQ, Jin H, Zhou SY, Shi JS, Jin F. TLR4 is a link between diabetes and Alzheimer's disease. Behav Brain Res. 2017:316:234-44.

12. Zhao XD, Wang FX, Cao WF, Zhang YH, Li Y. TLR4 signaling mediates AP-1 activation in an MPTP-induced mouse model of Parkinson's disease. Int Immunopharmacol. 2016;32:96-102.

13. Kawasaki T, Kawai T. Toll-like receptor signaling pathways. Front Immunol. 2014;5:461.

14. Roy A, Srivastava M, Saqib U, Liu D, Faisal SM, Sugathan S, Bishnoi S, Baig MS. Potential therapeutic targets for inflammation in toll-like receptor 4 (TLR4)-mediated signaling pathways. Int Immunopharmacol. 2016;40:79-89.

15. Murakami A, Ohigashi $\mathrm{H}$. Targeting NOX, INOS and COX-2 in inflammatory cells: chemoprevention using food phytochemicals. Int J Cancer. 2007; 121(11):2357-63.

16. Rahimifard M, Maqbool F, Moeini-Nodeh S, Niaz K, Abdollahi M, Braidy N, Nabavi SM, Nabavi SF. Targeting the TLR4 signaling pathway by polyphenols: a novel therapeutic strategy for neuroinflammation. Ageing Res Rev. 2017:36:11-9.

17. Guo H, Callaway JB, Ting JP. Inflammasomes: mechanism of action, role in disease, and therapeutics. Nat Med. 2015;21(7):677-87.

18. Bian F, Xiao Y, Zaheer M, Volpe EA, Pflugfelder SC, Li DQ, de Paiva CS. Inhibition of NLRP3 Inflammasome pathway by butyrate improves corneal wound healing in corneal alkali burn. Int J Mol Sci. 2017;18(3).

19. Tan MS, Yu JT, Jiang T, Zhu XC, Tan L. The NLRP3 inflammasome in Alzheimer's disease. Mol Neurobiol. 2013;48(3):875-82.

20. Yang JW, Yang SJ, Na JM, Hahn HG, Cho SW. 3-(Naphthalen-2yl(propoxy)methyl)azetidine hydrochloride attenuates NLRP3 inflammasome-mediated signaling pathway in lipopolysaccharidestimulated BV2 microglial cells. Biochem Biophys Res Commun. 2018; 495(1):151-6.

21. Pan MH, Lai CS, Ho CT. Anti-inflammatory activity of natural dietary flavonoids. Food Funct. 2010;1(1):15-31.
22. Leyva-Lopez N, Gutierrez-Grijalva EP, Ambriz-Perez DL, Heredia JB. Flavonoids as cytokine modulators: a possible therapy for inflammationrelated diseases. Int J Mol Sci. 2016;17(6).

23. Qin Z, Li S, Yao Z, Hong X, X J, Lin P, Zhao G, Gonzalez FJ, Yao X. Metabolic profiling of corylin in vivo and in vitro. J Pharm Biomed Anal. 2018;155:157-68.

24. Chopra B, Dhingra AK, Dhar KL. Psoralea corylifolia L. (Buguchi) - folklore to modern evidence: review. Fitoterapia. 2013;90:44-56.

25. Chen CC, Chen CY, Ueng SH, Hsueh C, Yeh CT, Ho JY, Chou LF, Wang TH. Corylin increases the sensitivity of hepatocellular carcinoma cells to chemotherapy through long noncoding RNA RAD51-AS1-mediated inhibition of DNA repair. Cell Death Dis. 2018;9(5):543.

26. Chen CY, Chen CC, Shieh TM, Hsueh C, Wang SH, Leu YL, Lian JH, Wang TH. Corylin suppresses hepatocellular carcinoma progression via the inhibition of epithelial-Mesenchymal transition, mediated by long noncoding RNA GAS5. Int J Mol Sci. 2018;19(2).

27. Lee SW, Yun BR, Kim MH, Park CS, Lee WS, Oh HM, Rho MC. Phenolic compounds isolated from Psoralea corylifolia inhibit IL-6-induced STAT3 activation. Planta Med. 2012;78(9):903-6.

28. Hung YL, Fang SH, Wang SC, Cheng WC, Liu PL, Su CC, Chen CS, Huang MY, Hua KF, Shen KH, et al. Corylin protects LPS-induced sepsis and attenuates LPS-induced inflammatory response. Sci Rep. 2017;7:46299.

29. Kim EK, Choi EJ. Pathological roles of MAPK signaling pathways in human diseases. Biochim Biophys Acta. 2010;1802(4):396-405.

30. Dinarello CA. Immunological and inflammatory functions of the interleukin1 family. Annu Rev Immunol. 2009;27:519-50.

31. Song L, Pei L, Yao S, Wu Y, Shang Y. NLRP3 Inflammasome in neurological diseases, from functions to therapies. Front Cell Neurosci. 2017;11:63.

32. Block ML, Zecca L, Hong JS. Microglia-mediated neurotoxicity: uncovering the molecular mechanisms. Nat Rev Neurosci. 2007;8(1):57-69.

33. Panthi S, Manandhar S, Gautam K. Hydrogen sulfide, nitric oxide, and neurodegenerative disorders. Transl Neurodegener. 2018;7:3.

34. Andreasson K. Emerging roles of PGE2 receptors in models of neurological disease. Prostaglandins Other Lipid Mediat. 2010;91(3-4):104-12.

35. Ryan JC, Cross CA, Van Dolah FM. Effects of COX inhibitors on neurodegeneration and survival in mice exposed to the marine neurotoxin domoic acid. Neurosci Lett. 2011;487(1):83-7.

36. Consonni A, Morara S, Codazzi F, Grohovaz F, Zacchetti D. Inhibition of lipopolysaccharide-induced microglia activation by calcitonin gene related peptide and adrenomedullin. Mol Cell Neurosci. 2011;48(2):151-60.

37. Scheiblich H, Schlutter A, Golenbock DT, Latz E, Martinez-Martinez P, Heneka MT. Activation of the NLRP3 inflammasome in microglia: the role of ceramide. J Neurochem. 2017;143(5):534-50

Ready to submit your research? Choose BMC and benefit from:

- fast, convenient online submission

- thorough peer review by experienced researchers in your field

- rapid publication on acceptance

- support for research data, including large and complex data types

- gold Open Access which fosters wider collaboration and increased citations

- maximum visibility for your research: over $100 \mathrm{M}$ website views per year

At BMC, research is always in progress.

Learn more biomedcentral.com/submissions 